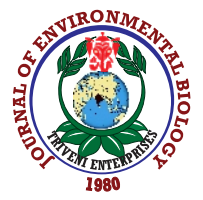

\title{
2,6-and 3,5-dimethylaniline-induced mutagenesis in Chinese hamster ovary cells expressing human cytochrome P450 1A2 and sulfotransferase
}

\section{M.Y. Kim*}

Toxicology Laboratory, Faculty of Biotechnology (Biomaterials), College of Applied Life Science, SARI, Jeju National University, Jeju, 63243, Republic of Korea

*Corresponding Author Email : jeffmkim@jejunu.ac.kr

\section{Abstract}

Aim: The aim of this study was to test the hypothesis that human cytochrome P450 1A2 (CYP1A2) and sulfotransferase (SULT) contribute to the phase I and II bioactivation of 2,6-dimethylaniline (2,6-DMA) and 3,5-dimethylaniline (3,5-DMA) in affecting the incidence of genotoxicity.

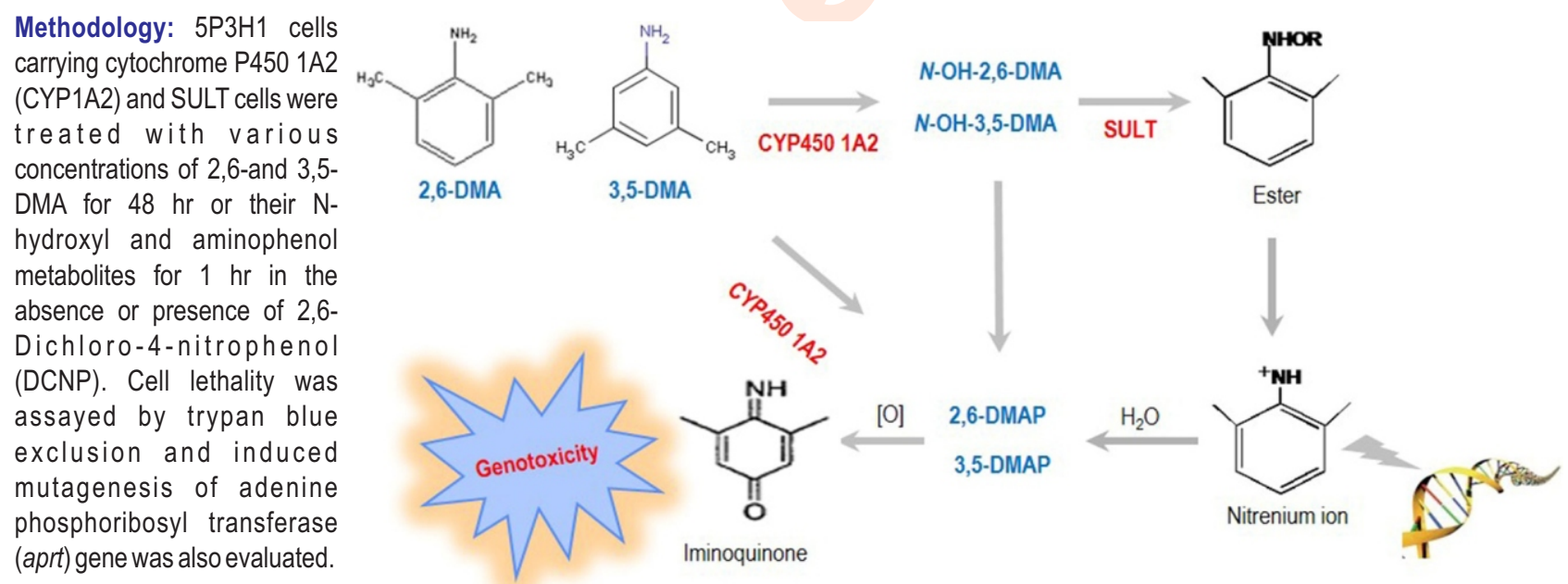

Results: A significant dose-

dependent increase in cytotoxicity and mutant fraction was observed after treatment with 2,6- and 3,5-DMA, and their metabolites; N-hydroxy and aminophenol metabolites are more potent than the parent compounds. Addition of sulfotransferase inhibitor DCNP decreased the cytotoxic and mutagenic effects of 2,6- and 3,5-DMA, and their metabolites in a dose-dependent manner.

Interpretation: This research indicate that 2,6 and 3,5-DMA are mutagenic, and their toxicity in model systems depend on metabolic activation. This activation is mediated by CYP1A2 and SULT enzymes.

Key words: Chinese hamster, Cytochrome, Dimethylaniline, Ovary cells, Sulfotransferase

How to cite : Kim, M.Y.: 2,6- and 3,5-dimethylaniline-induced mutagenesis in Chinese hamster ovary cells expressing human cytochrome P450 $1 \mathrm{~A} 2$ and sulfotransferase. J. Environ. Biol., 41, 581-585 (2020). 


\section{Introduction}

Humans can be exposed to dimethylaniline (DMA) via various sources like tobacco smoke, some pesticides, anaesthetics and permanent hair dye. The carcinogenic potential of some DMAs has been previously reported, and there is sufficient evidence for the carcinogenicity of 2,6-DMA in experimental animals (Haseman and Hailey, 1997). Moreover, two epidemiologic studies conducted with DMA isomers showed that levels of haemoglobin adducts of 2,6- and 3,5-DMA in peripheral blood samples are significantly associated with an increased risk of bladder cancer in humans (Gan et al., 2004; Tao et al., 2013). However, limited efforts have been made to study the genotoxic effect of 2,6- and 3,5-DMA, and their metabolites. In bacterial reverse mutation assays and in vitro chromosomal aberration tests, positive results were for 2,6- and 3,5-DMA with the addition of metabolic activation system (rat liver $\$ 9$ mix) (Zeiger et al., 1988; Kohara et al., 2018). In previous studies, induction of gene mutations by 2,6- and 3,5-DMA and their metabolites has been reported in the gpt of AS52 (Chao et al., 2012) and, HPRT and TK1 genes of TK6 (Chao et al., 2012) cells with human S9.

Metabolism of chemical carcinogens plays a principal role in the aetiology of cancer (Gonzalez andKorzekwa, 1994). A better understanding of the properties of carcinogen metabolizing enzymes will, thus, aid in studies of human risk assessment. Arylamines require metabolic activation, usually in the liver, to be transformed into fully carcinogenic agents (Hecht, 2003). They are oxidized to $\mathrm{N}$-hydroxylamines in vivo and react with hemoglobin to form adducts that may persist as long as the hemoglobin adducts remains in circulation (Skipper et al., 2010). Many heterocyclic amines, formed in meat during pyrolysis, are activated by cytochrome P450 1A2 (CYP1A2)-catalyzed Nhydroxylation, including 2-amino-1-methyl-6-phenylimidazo[4,5b]pyridine (PhIP) and 2-amino-3,8-dimethylimidazo[4,5flquinoxaline (MelQx) (Guengerich, 2006). For xenobiotics such as $\mathrm{N}$-hydroxy arylamines, N-hydroxy heterocyclic amines, and hydroxymethyl polycyclic aromatic hydrocarbons, sulfonation by sulfotransferase (SULT) is a metabolic activation process leading to highly reactive electrophiles that are both mutagenic and carcinogenic (Gamage et al., 2006).

\section{Materials and Methods}

Cell cultures: 5P3H1 cells were received as a generous gift from Dr. Gerald N. Wogan (Massachusetts Institute of Technology, Cambridge, MA, USA), derived from $\mathrm{CHO}$ cell line AA8, functionally heterozygous at the aprt locus ( $\mathrm{Wu}$ et al., 2000; Wu et al., 2003). The 5P3H1 cell line carries the mouse CYP1A2 and a human aryl sulfotransferase HAST1 isolated from human liver. Details concerning the construction and characterization of these cell lines has been described previously (Wu et al., 2003; Wu et al., 1997). Prior to each experiment, cells were incubated for 2 days in a medium containing CAAT $(10 \mu \mathrm{M}$ cytidine, $100 \mu \mathrm{M}$ adenine, $1 \mu \mathrm{M}$ aminopterin and $17.5 \mu \mathrm{M}$ thymidine) and 2-5 days in TAC medium (thymidine, adenine and cytidine) to reduce the background aprt mutant fraction (Fujimori et al., 1992). All cells were routinely maintained by monolayer culture in a-minimal essential medium containing L-glutamine supplemented with penicillin (100 unitsml $\left.{ }^{-1}\right)$, streptomycin (100 $\mu \mathrm{gml}^{-1}$ ) and $10 \%$ heat-inactivated fetal bovine serum (Atlanta Biologicals, Lawrenceville, GA) in a humidified atmosphere with $5 \% \mathrm{CO}_{2}$ at $37^{\circ} \mathrm{C}$. All cell culture reagents were purchased from Lonza (Walkersville, MD).

Cell viability and aprt mutation assay: N-hydroxy and aminophenol metabolites of 2,6- and 3,5-DMA were synthesized as described previously (Chao et al., 2012). 2,6- and 3,5-DMA were purchased from Sigma Chemical (St Louis, MO, USA) and Acros Organics (Geel, Belgium). 2,6- and 3,5-DMA, and their metabolites dissolved in dimethyl sulfoxide (DMSO, SigmaAldrich, MO, USA) was added to exponentially growing cells in $100 \mathrm{~mm}$ tissue culture dish containing $0.5 \times 10^{6}$ cells in $10 \mathrm{ml}$ of media. $5 \mathrm{P} 3 \mathrm{H} 1$ cells were exposed to $0,5,10,25$ and $50 \mu \mathrm{M}$ of parent compounds for $48 \mathrm{hr}$ or N-hydroxy and aminophenol metabolites for $1 \mathrm{hr}$ in the absence or presence of $0.2 \mathrm{mM}$ 2,6Dichloro-4-nitrophenol (DCNP, Cole-Parmer, Illinois, USA). A selective SULT inhibitor DCNP was further used to inhibit the sulfation pathway for bioactivation of 2,6- and 3,5-DMA, and their metabolites. In the preliminary experiment, $0.2 \mathrm{mM}$ DCNP itself did not have any cytotoxic and mutagenic effect on the sulfotransferase cells (data not shown).

The control culture was treated with the same volume of DMSO for $48 \mathrm{hr}$. The final concentration of DMSO to which cells were exposed was less than $0.1 \%$. Test concentrations of 2,6- and 3,5-DMA, and their metabolites were established by MTT assay (data not shown). Following treatment, the cells were rinsed twice with PBS and removed with trypsin. Cells were allowed to recover for $24 \mathrm{hr}$ before determining survival by trypan blue exclusion, and maintained in regular medium for phenotypic expression. At the end of 3 days phenotypic expression, cultures were plated for cloning efficiency and mutation. Total $6 \times 10^{5}$ cells from each group

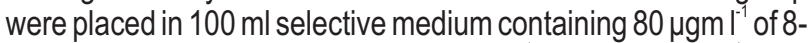
AA and plated at 600000 cells $10 \mathrm{ml}^{-1} 100 \mathrm{~mm}^{\text {dish }}{ }^{-1}$ (ten replicates) for determining mutagenicity after 14 days. In addition, each mutant was rescreened in selective media in order to confirm the stability of mutant phenotype. Cloning efficiency dishes were seeded with 200 cells $10 \mathrm{ml}^{-1} 100 \mathrm{~mm} \mathrm{dish}^{-1}$ in triplicate and allowed to grow until colonies were visible for 8 days in the absence of selecting agent. Mutation fraction was calculated as ratio of mean cloning efficiency in selective medium to that in non-selective medium. In this study, cells treated with 0.2 $\mu \mathrm{M}$ PhIP (Toronto Research Chemicals, Ontario, Canada) for 48 hr served as a positive control.

Statistical analysis: All experiments were repeated three times. Two-tailed Student's t-test (SPSS for Windows, 12.0, SPSS Inc. Chicago, IL, USA) write clearly, and $p$ value less than 0.05 were considered significant.

\section{Results and Discussion}

2,6-DMA and its hydroxy and aminophenol metabolites were evaluated with $5 \mathrm{P} 3 \mathrm{H} 1$ cells to determine their ability to produce cell killing and mutations with/without co-treatment of 
sulfotransferase inhibitor DCNP. Hemizygous mutant $\mathrm{CHO}$ aprt gene was used as a target locus for mutation assay. aprt is constitutively expressed "housekeeping" gene that codes for a purine salvage-pathway enzyme (Bollée et al., 2010). The small size of Chinese hamster aprt gene, its convenient distribution of restriction sites, and absence of aprt pseudogenes in $\mathrm{CHO}$ cells greatly facilitate molecular analysis of aprt recombinants (Boll'ee et al., 2010). As shown in Table1, one or forty eight hour treatment of 5P3H1 cells with 2,6-DMA, N-OH-2,6-DMA and 2,6-DMAP resulted in an approximately linear dose-dependent increase in MF at the aprt locus, to a maximum for $10 \mu \mathrm{M}$ of $4.29 \times 10^{-5}$ for 2,6 DMA or $13.1 \times 10^{-5}$ for N-OH-2,6-DMA or $16.87 \times 10^{-5}$ for $2,6-$ DMAP, respectively, as compared to a spontaneously fraction of $3.34 \times 10^{-5}$ accompanied with dose-dependent decrease in cell survival (Fig. 1). Cell survival and MF induced by 2,6-DMA and its metabolites were affected by sulfotransferase activity. DCNP is a potent selective inhibitor for human phenol sulfotransferases (Wu et al., 2000). Addition of DCNP caused an increase cell growth of 4- and 6-fold for $50 \mu \mathrm{M} \mathrm{N}-\mathrm{OH}-2,6-\mathrm{DMA}$ and 2,6-DMAP respectively (Fig. 1), and a decrease in MF by 3.1-and 4.3-fold for
$10 \mu \mathrm{M} \mathrm{N}-\mathrm{OH}-2,6-\mathrm{DMA}$ and 2,6-DMA compared with values obtained without DCNP (Fig. 1).

Sulfonation is an important reaction in the metabolism of numerous xenobiotics, drugs, and endogenous compounds. Sulfonation has been shown to be important in the activation of a range of compounds such as aminoazo dyes, benzidines, heterocyclic amines, hydroxymethyl polycyclic aromatic hydrocarbons, terpenes, b-aminoethyl alcohols, and 2nitropropane (Gamage et al., 2006). In consistent with our results, these studies have shown that sulfotransferases are very selective in their activation of promutagens (Gamage et al., 2006). 5P3H1 cell line also showed dose-dependent cytotoxicity and aprt mutants induced by 3,5-DMA and its hydroxy and aminophenol metabolites (Fig. 2, Table 2). At 10 $\mu \mathrm{M}$ 3,5-DMA, N-OH-3,5-DMA and 3,5-DMAP, induced MFs in the aprt genes were $3.71 \times 10^{-5}, 17.50 \times 10^{-5}$ and $29.90 \times 10^{-5}$, 1.1-, 5.2- and 9-fold higher than background $\left(3.34 \times 10^{-5}\right)$ (Table2). Like results of 2,6-DMA and its metabolites, cytotoxicity and MF induced by 3,5-DMA and its metabolites

Table 1: Mutation fraction after treatment with 2,6-DMA for $48 \mathrm{hr}$ or its metabolites for $1 \mathrm{hr}$ in $5 \mathrm{P} 3 \mathrm{H} 1$ and AA8 cells

\begin{tabular}{|c|c|c|c|c|c|}
\hline \multirow[b]{2}{*}{ Cells } & \multirow[b]{2}{*}{ Groups } & \multicolumn{4}{|c|}{ Mutation fraction $\left(\times 10^{-5}\right)$} \\
\hline & & $5 \mu \mathrm{M}$ & $10 \mu \mathrm{M}$ & $50 \mu \mathrm{M}$ & $100 \mu \mathrm{M}$ \\
\hline $5 \mathrm{P} 3 \mathrm{H} 1$ & $\begin{array}{l}\text { 2,6-DMA } \\
\text { 2,6-DMA+DCNP } \\
\text { N-OH-2,6-DMA } \\
\text { N-OH-2,6-DMA+DCNP } \\
\text { 2,6-DMAP } \\
\text { 2,6-DMAP+DCNP }\end{array}$ & $\begin{array}{l}4.42 \pm 0.345 \\
3.42 \pm 0.249^{*} \\
8.12 \pm 1.074 \\
4.08 \pm 0.197^{*} \\
4.65 \pm 0.818 \\
3.34 \pm 0.609^{*}\end{array}$ & $\begin{array}{l}4.29 \pm 0.317 \\
3.52 \pm 0.462^{*} \\
13.10 \pm 1.819 \\
4.16 \pm 0.807^{*} \\
16.87 \pm 1.610 \\
3.95 \pm 0.577^{*}\end{array}$ & & \\
\hline AA8 & $\begin{array}{l}\text { 2,6-DMA } \\
\text { N-OH-2,6-DMA } \\
\text { 2,6-DMAP }\end{array}$ & & & $\begin{array}{l}3.11 \pm 0.770 \\
3.02 \pm 0.643 \\
3.07 \pm 0.114\end{array}$ & $\begin{array}{l}3.13 \pm 3127 \\
3.21 \pm 0.584 \\
3.16 \pm 0.338\end{array}$ \\
\hline
\end{tabular}

Each values is expressed as mean of three replicate \pm standard deviation. Spontaneous MF was $3.34 \pm 0.268(5 \mathrm{P} 3 \mathrm{H} 1)$ and $2.90 \pm 0.271(\mathrm{AA} 8) \times 10^{-5} .{ }^{*} p<$ 0.05 compared to $2,6-\mathrm{DMA}$ and its metabolites without DCNP (5P3H1)

Table 2: Mutation fraction after treatment with 3,5-DMA for $48 \mathrm{hr}$ or its metabolites for $1 \mathrm{hr}$ in 5P3H1 and AA8 cells

\begin{tabular}{|c|c|c|c|c|c|}
\hline \multirow[b]{2}{*}{ Cells } & \multirow[b]{2}{*}{ Groups } & \multicolumn{4}{|c|}{ Mutation fraction $\left(\times 10^{-5}\right)$} \\
\hline & & $5 \mu \mathrm{M}$ & $10 \mu \mathrm{M}$ & $50 \mu \mathrm{M}$ & $100 \mu \mathrm{M}$ \\
\hline $5 \mathrm{P} 3 \mathrm{H} 1$ & $\begin{array}{l}\text { 3,5-DMA } \\
\text { 3,5-DMA+DCNP } \\
\text { N-OH-3,5-DMA } \\
\text { N-OH-3,5-DMA+DCNP } \\
\text { 3,5-DMAP } \\
\text { 3,5-DMAP+DCNP }\end{array}$ & $\begin{array}{l}3.65 \pm 0.463 \\
3.73 \pm 0.625 \\
9.06 \pm 2.450 \\
5.29 \pm 1.009^{*} \\
15.30 \pm 1.310 \\
4.49 \pm 0.303^{*}\end{array}$ & $\begin{array}{l}3.71 \pm 0.238 \\
4.18 \pm 0.441^{*} \\
17.50 \pm 3.092 \\
6.18 \pm 0.493^{*} \\
29.90 \pm 4.681 \\
8.94 \pm 0.640^{*}\end{array}$ & & \\
\hline AA8 & $\begin{array}{l}\text { 3,5-DMA } \\
\text { N-OH-3,5-DMA } \\
\text { 3,5-DMAP }\end{array}$ & & & $\begin{array}{l}3.33 \pm 0.521 \\
3.01 \pm 0.362 \\
3.04 \pm 0.247\end{array}$ & $\begin{array}{l}3.40 \pm 0.514 \\
3.22 \pm 0.263 \\
3.41 \pm 0.246\end{array}$ \\
\hline
\end{tabular}

Each values is expressed as mean of three replicate \pm standard deviation. Spontaneous MF was $3.34 \pm 0.268(5 \mathrm{P} 3 \mathrm{H} 1)$ and $2.90 \pm 0.271(\mathrm{AA} 8) \times 10^{-5} .{ }^{*} p<$ 0.05 compared to $3,5-\mathrm{DMA}$ and its metabolites without DCNP (5P3H1) 
A

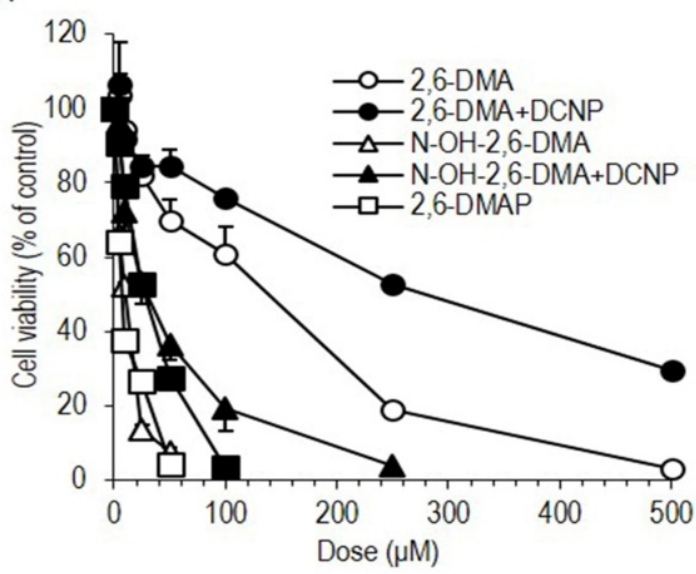

B

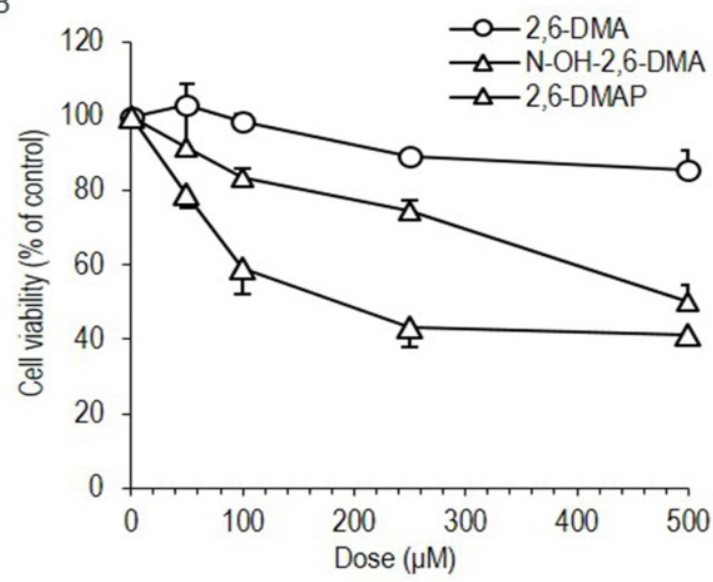

Fig. 1: Dose-dependent of cell survival after treatment with 2,6-DMA for $48 \mathrm{hr}$ or its metabolites for $1 \mathrm{hr}$ in $5 \mathrm{P} 3 \mathrm{H} 1 \mathrm{(A)}$ and Aa8 (B) cells. Survival was determined by trypan blue assay $24 \mathrm{hr}$ after treatment. Data represent mean of three replicates \pm S.D.

were sharply decreased following co-treatment with DCNP (Fig. 2, Table 2). The mutant factor in the positive control 5P3H1 cells treated with $0.2 \mu \mathrm{M}$ PhIP for $48 \mathrm{hr}$ was $77.3 \times 10^{-5}$.

A number of approaches are available to assess the role of drug and xenobiotic metabolizing enzymes in activation and/or inactivation of chemicals that might act as potential carcinogens (García-Suástegui et al., 2017; Duvai et al., 2016). Heterologous expression of human enzymes in a cell system used for mutagenicity testing has the advantage that metabolites are generated inside the target cell and, thus, enable study of the role of metabolizing enzymes in bioactivation of chemicals (GarcíaSuástegui et al., 2017; Duvai et al., 2016). In this study, we used CHO AA8-derived $5 \mathrm{P} 3 \mathrm{H} 1$ cells, which was able to express active CYP1A2 and SULT. With these cells we were able to detect bioactivation of 2,6- and 3,5-DMA. 5P3H1 cell line was more sensitive to the genotoxic effect of these two monocyclic amines
A

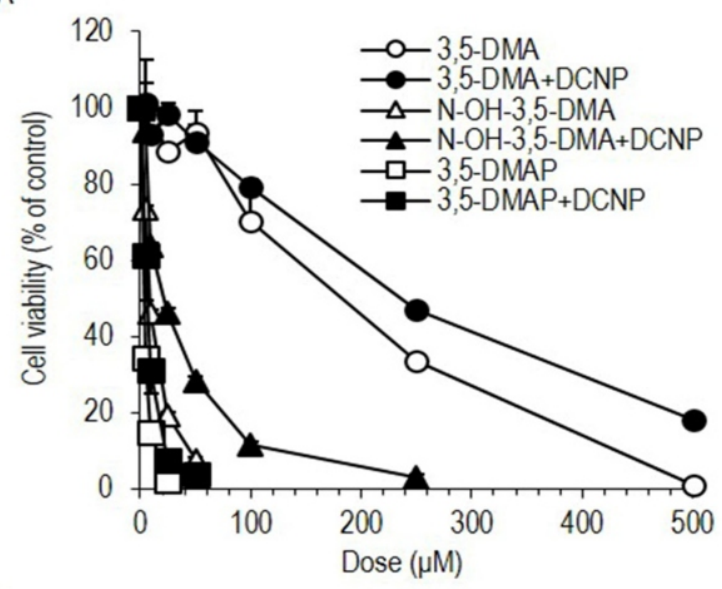

B

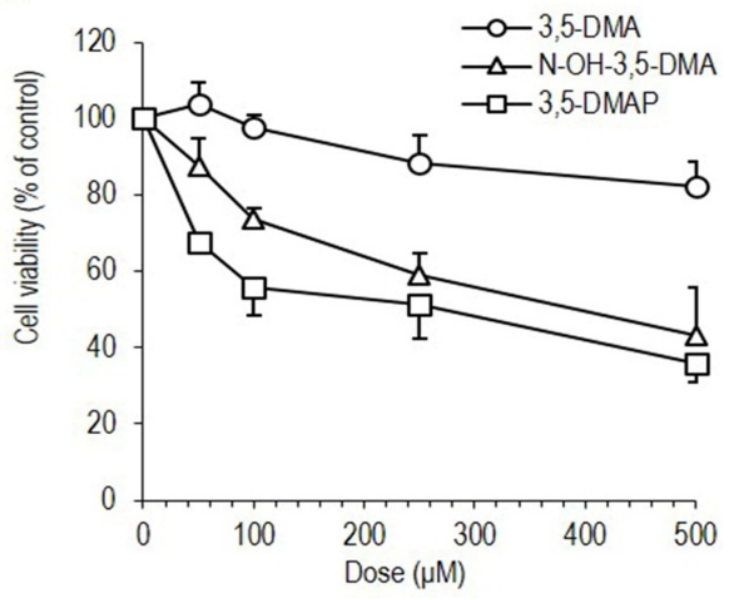

Fig. 2: Dose-dependent of cell survival after treatment with 3,5-DMA for $48 \mathrm{hr}$ or its metabolites for $1 \mathrm{hr}$ in $5 \mathrm{P} 3 \mathrm{H} 1$ (A) and AA8 (B) cells. Survival was determined by trypan blue assay $24 \mathrm{hr}$ after treatment. Data represent mean of three replicates \pm S.D.

and their metabolites relative to parental AA8 line. Exposure to 10 $\mu \mathrm{M}$ of 2,6-DMAP, reduced viability and increased MF in $5 \mathrm{P} 3 \mathrm{H} 1$ to $37.5 \%$ and $16.87 \times 10^{-5}$, respectively, whereas comparable values after treatment with $50 \mu \mathrm{M}$ of 2,6-DMAP in AA8 were $79.1 \%$ and $3.07 \times 10^{-5}$ (Table 1, Fig. 1). In addition, cell viability and mutation fraction were $14.8 \%$ and $29.9 \times 10^{-5}$ in $5 \mathrm{P} 3 \mathrm{H} 1$ cells after a dose of $10 \mu \mathrm{M} 3,5$-DMAP, compared to $67.4 \%$ and $3.04 \times 10^{-5}$ after treatment with $50 \mu \mathrm{M} 3,5$-DMAP in AA8 cells (Table 2, Fig. 2). It is clear from the data that 2,6- and 3,5-DMA is more genotoxic following oxidative metabolism catalyzed by CYP1A2 and SULT.

In this study, we employed Chinese hamster ovary (CHO)-derived 5P3H1 cell line in which both CYP1A2 and SULT were introduced for determining the role of these enzymes in metabolic activation and genotoxicity of two monocyclic amines, 2,6- and 3,5-DMA. Based on their heterozygosity at the adenine phosphoribosyltransferase (aprt) locus, they can be used for 
mutational analysis based on selection with 8-azaadenine (8-AA).

The present study indicates that 2,6- and 3,5-DMA investigated appear to have significant genotoxic potential. The evidence also suggests that CYP1A2 and SULT were effective enzymes leading to bioactivation of 2,6- and 3,5-DMA, it strongly enhanced the cytotoxicity and mutagenicity via formation of hydroxyl and aminophenol metabolites of 2,6- and 3,5-DMA.

\section{Acknowledgment}

This research was supported by Basic Science Research Program (2017R1D1A1B03028849, 2016R1A6A1A03012862 and 2014R1A1A2056292) through the National Research Foundation of Korea (NRF) funded by the Ministry of Education, Science and Technology, Republic of Korea.

\section{References}

Bollée, G., Cécile Dollinger, Lucile Boutaud, Delphine Guillemot, Albert Bensman, Jérôme Harambat, Patrice Deteix, Michel Daudon, Bertrand Knebelmann and Irène Ceballos-Picot : Phenotype and genotype characterization of adenine phosphoribosyltransferase deficiency. JASN, 21, 679-688 (2010).

Chao, M.W., M.Y. Kim, W. Ye, J. Ge, L.J. Trudel, C.L. Belanger, P.L. Skipper, B.P. Engelward, S.R. Tannenbaum and G.N. Wogan: Genotoxicity of 2,6- and 3,5-dimethylaniline in cultured mammalian cells: The role of reactive oxygen species. Toxicol. Sci., 130, 48-59 (2012).

Duval, R., X. Xu, L.C. Bui, C. Mathieu, E. Petit, K. Cariou, R.H. Dodd, J.M. Dupret and F. Rodrigues-Lima: Identification of cancer chemopreventive isothiocyanates as direct inhibitors of the arylamine $\mathrm{N}$-acetyltransferase-dependent acetylation and bioactivation of aromatic amine carcinogens. Oncotarget., 7, 8688-8699 (2016).

Fujimori, A., A. Tachibana and K. Tatsumi :Allelic losses in mutations at the aprt locus of human lymphoblastoid cells. Mutat. Res., 269, 5562 (1992).

Gamage, N., A. Barnett, N. Hempel, R.G. Duggleby, K.F. Windmill, J.L. Martin and M.E. McManus: Human sulfotransferases and their role in chemical metabolism. Toxicol. Sci., 90, 5-22 (2006)

Gan, J., P.L. Skipper, M. Gago-Dominguez, K. Arakawa, R.K. Ross, M.C. Yu and S.R. Tannenbaum: Alkylaniline-hemoglobin adducts and risk of non-smoking-related bladder cancer. J. Natl. Cancer Inst., 96, 1425-1431 (2004).

García-Suástegui, W.A., L.A. Ramos-Chávez, M. Rubio-Osornio, M. Calvillo-Velasco, J.A. Atzin-Méndez, J. Guevara and D. Silva-Adaya: The role of CYP2E1 in the drug metabolism or bioactivation in the brain. Oxid. Med. Cell. Longev., 2017, 14 (2017).

Gonzalez, F.J. and K.R. Korzekwa: Cytochromes P450 expression systems. Annu. Rev. Pharmacol. Toxicol., 35, 369-390 (1995).

Guengerich, F.P.: Cytochrome P450s and other enzymes in drug metabolism and toxicity. AAPS. J., 8, E101-111 (2006).

Haseman, J.K. and J.R. Hailey: An update of the National Toxicology Program database on nasal carcinogens. Mutat. Res., 380, 3-11 (1997).

Hecht, S. :Tobacco carcinogens, their biomarkers and tobacco induced cancer. Nat. Rev. Cancer, 3, 733-744 (2003).

Kohara, A., M. Matsumoto, A. Hirose, M. Hayashi, M. Honma and T. Suzuki: Mutagenic properties of dimethylaniline isomers in mice as evaluated by comet, micronucleus and transgenic mutation assays. Genes Environ., 40, 18 (2018).

Skipper, P.L, M.Y. Kim, H.L.P. Sun, G.N. Wogan and S.R. Tannenbaum: Monocyclic aromatic amines as potential human carcinogens: Old is new again. Carcinogenesis, 31, 50-58 (2010).

Tao, L., B.W. Day, B. Hu, Y.B. Xiang, R. Wang, M.C. Stern, M. GagoDominguez, V.K. Cortessis, D.V. Conti, D.V.D. Berg, M.C. Pike, Y.T. Gao, M.C. Yu and J.M. Yuan: Elevated 4-aminobiphenyl and 2,6-dimethylaniline hemoglobin adducts and increased risk of bladder cancer among lifelong nonsmokers-The Shanghai bladder cancer study. Cancer Epidemiol. Biomark. Prev., 22, 937945 (2013).

Wu, R.W., F.N. Panteleakos and J.S. Felton: Development and characterization of $\mathrm{CHO}$ repair-proficient cell lines for comparative mutagenicity and metabolism of heterocyclic amines from cooked food. Environ. Mol. Mutagen., 41, 7-13 (2003).

Wu, R.W., F.N. Panteleakos, S. Kadkhodayan, R. Bolton-Grob, M.E. McManus and J.S. Felton: Genetically modified Chinese hamster ovary cells for investigating sulfotransferase-mediated cytotoxicity and mutation by 2-amino-1-methyl-6- phenylimidazo [4,5b]pyridine. Environ. Mol. Mutagen., 35, 57-65 (2000).

Wu, R.W., J.D. Tucker, K.J. Sorensen, L.H. Thompson and J.S. Fellton: Differential effect of acetyltransferase expression on the genotoxicity of heterocyclic amines in $\mathrm{CHO}$ cells. Mutat. Res., 390, 93-103 (1997)

Zeiger, E., B. Anderson, S. Haworth, T. Lawlor and K. Mortelmans: Salmonella mutagenicity tests: IV. Results from the testing of 300 chemicals. Environ. Mol. Mutagen., 11, 1-157 (1988). 